\title{
ASSOCIATION BETWEEN DIET, BODY IMAGE, AND SELF- ESTEEM AMONG FEMALE STUDENTS IN JAKARTA
}

\author{
Frima Elda
}

Indonesia Sport Nutritionist Association

\begin{abstract}
Background: Body image dissatisfaction, negative mood states such as depression and stress, low self-esteem, and personality traits are contributed to undesired physiologic disorder, such as eating disorder. This study aimed to analyze the association between diet, body image, and self-esteem among female students in Jakarta.

Subjects and Method: This was a cross sectional study conducted at High School in Jakarta. A total of 504 female students aged 15-17 years was selected for this study. The dependent variable was self-esteem. The independent variables were diet and body image. The data of diet were collected using restrained eating scale of the Dutch Eating Behaviors and the Binge Scale questionnaires. Body image were measured using the Contour Drawing Rating Scale. Self-esteem data were measured using the Rosenberg Self-Esteem Scale. The data were analyzed using ANCOVA.

Results: Diet and body image were associated with self-esteem.

Conclusion: Self-esteem is associated with diet and body image among female students.
\end{abstract}

Key words: diet, body image, self-esteem, female student

Correspondence:

Frima Elda. Indonesian Sport Nutritionist Association. Email: frima_elda84@yahoo.com. Mobile: 085272802345 .

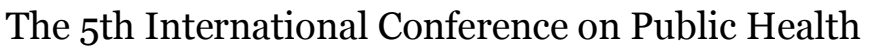

Best Western Premier Hotel, Solo, Indonesia, February 13-14, 2019| 164 https://dol.org/10.26911/theicph.2019.02.09 